\title{
Deuterium depth profiling in graphite tiles not exposed to hydrogen discharges before air ventilation of JT-60U
}

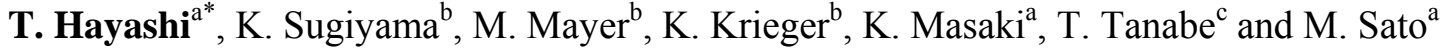 \\ ${ }^{a}$ Japan Atomic Energy Agency, Mukouyama 801-1, Naka, Ibaraki 311-0193, Japan \\ ${ }^{b}$ Max-Planck-Institut für Plasmaphysik, EURATOM Association, Germany \\ ${ }^{c}$ Interdisciplinary Graduate School of Engineering Sciences, Kyushu University, Japan
}

Depth profiles of deuterium trapped in graphite tiles not exposed to hydrogen

discharges just before air ventilation of JT-60U were determined based on the $\mathrm{D}\left({ }^{3} \mathrm{He}, \mathrm{p}\right)^{4} \mathrm{He}$ resonant nuclear reaction analysis. The samples were taken from the $\mathrm{W}$-shaped divertor. The maximum depth of analysis is about $1.4 \times 10^{24}$ carbon atoms $/ \mathrm{m}^{2}$, corresponding to a linear depth of $16 \mu \mathrm{m}$ for the density of $1.7 \times 10^{3} \mathrm{~kg} / \mathrm{m}^{3}$. The highest concentration (19 at.\%) was found at the surface of the inner divertor area, which was significantly higher than that exposed to $\mathrm{H}$ discharges at the same location. However in the deeper region, the deuterium concentrations without $\mathrm{H}$ discharges were lower than those with $\mathrm{H}$ discharges in 3 of 4 samples. These results indicate that hydrogen discharges can remove deuterium trapped only in the shallow region.

JNM keywords: C0100 (Carbon), D0500 (Divertor Materials), H0400 (Hydrogen), P0500 (Plasma-Materials Interaction), T0900 (Tritium)

PSI-18 keywords: Deuterium inventory, Carbon-based materials, JT60U, Divertor, Surface analysis

PACS: 28.52.Fa, 28.52.Nh, 52.40.Hf, 52.55.Fa

*Corresponding author address: 801-1, Mukouyama, Naka, Ibaraki, 311-0102, Japan.

*Corresponding author E-mail: hayashi.takao@jaea.go.jp

Presenting author: Takao Hayashi

Presenting author e-mail: hayashi.takao@jaea.go.jp 


\section{Introduction}

Tritium (T) and deuterium (D) are used as fuels of plasma discharges in a fusion reactor. A fraction of tritium is retained both on the surface and inside of the plasma-facing materials. From the point of view of radiological safety, one of the most important outstanding issues is to understand tritium behavior and to predict the tritium inventory of in-vessel components. Much research regarding tokamak experimental device plasma-wall interaction and erosion/deposition has been reported [1-5]. In the JAERI Tokamak-60 Upgrade (JT-60U), deuterium discharges have been performed. In order to estimate the tritium retention in future tokamak reactors including ITER, it is very important to investigate the retention characteristics of deuterium in carbon tiles used in JT-60U.

Recently, detailed analyses of deuterium and hydrogen in plasma-facing graphite tiles of JT-60U have been performed using secondary ion mass spectroscopy (SIMS), thermal desorption spectroscopy (TDS), nuclear reaction analysis (NRA), elastic recoil detection (ERD) and a scanning electron microscope (SEM) [6-11]. Although the SIMS analysis gives depth profiles of hydrogen isotopes together with impurities, it is hard to give quantitative concentrations.

In this paper, we have made a quantitative depth analysis of deuterium in plasma-facing graphite tiles used in JT-60U by means of the $\mathrm{D}\left({ }^{3} \mathrm{He}, \mathrm{p}\right)^{4} \mathrm{He}$ resonant nuclear reaction. The analyzed samples were not exposed to hydrogen $(\mathrm{H})$ discharges just before air ventilation. The effect of hydrogen cleaning discharges was investigated by comparing the D 
concentrations of graphite tiles exposed or not exposed to $\mathrm{H}$ discharges.

\section{Experimental}

\subsection{Samples}

Figures 1(a) and (b) show the poloidal locations of analyzed samples in the cross sections of the W-shaped divertor areas of JT-60U. The under bar of the sample name means that the tile was not exposed to $\mathrm{H}$ discharges just before air ventilation. Specifically, Fig 1(b) show the sample locations not exposed to H discharges. In 1998, the outer pumping slot was added in the private region of the $\mathrm{W}$-shaped divertor. Since then, plasma in the private flux region was pumped through a full toroidal inner and outer slot. The sampling positions were almost same between with and without $\mathrm{H}$ discharges except for the outer dome wing tile (DM2).

Carbon fiber composite (CFC) materials with high thermal conductivity were used for the divertor tiles. CFC tiles were shown gray color in the fig. 1 (a) and (b). All other tiles were made of isotropic fine grain graphite. Plasma operation periods for each tile were also shown in Fig. 1. Specifically, divertor tiles without $\mathrm{H}$ discharges were exposed to plasma from January 1999 to June 2002. In this operation period, about 7800 pulse discharge experiments ( $\sim 6000$ deuterium discharges and $\sim 1200$ hydrogen discharges) were carried out with the W-shaped divertor configurations. The hydrogen discharges were carried out in 1999, 2000 and 2001, and not performed in 2002 including just before of the air ventilation. On the other 
hand, in the operation period from June 1997 to October 1998, about 300 hydrogen discharges were performed just before the air ventilation, even though the total number of the plasma discharges was about 4300 ( $\sim 3600$ deuterium discharges and $\sim 700$ hydrogen discharges).

The operational temperature of the vacuum vessel was $\sim 570 \mathrm{~K}$ throughout the entire period. The temperature of the strike point at the outer divertor (OD) was higher than that of the inner divertor (ID). The maximum surface temperatures of the outer and the inner divertor tiles were estimated from the bulk temperature measured by thermocouples embedded at a depth of $6 \mathrm{~mm}$ to be $\sim 1400 \mathrm{~K}$ and $\sim 1000 \mathrm{~K}$, respectively [9]. The maximum surface temperature of the dome region (DM1 and DM2) was estimated to be $\sim 800 \mathrm{~K}$.

\subsection{Nuclear reaction analysis (NRA)}

Deuterium depth profiles were determined by using the $\mathrm{D}\left({ }^{3} \mathrm{He}, \mathrm{p}\right)^{4} \mathrm{He}$ resonant nuclear reaction. Because the cross section of the $\mathrm{D}\left({ }^{3} \mathrm{He}, \mathrm{p}\right)^{4} \mathrm{He}$ nuclear reaction has a broad resonant peak at a ${ }^{3} \mathrm{He}$ energy of about $0.6 \mathrm{MeV}$, the deuterium depth profiles can be obtained by varying the incident energy of the ${ }^{3} \mathrm{He}$ beam. The ${ }^{3} \mathrm{He}$ beam at energies from 0.69 to 3.5 $\mathrm{MeV}$ was produced by a $3 \mathrm{MV}$ tandem accelerator at IPP Garching, Germany. Samples with a size of $10 \times 10 \times 1 \mathrm{~mm}^{3}$ were cut from the tiles and were used for ion beam analysis. The beam spot area and beam current were $\sim 1 \times 1 \mathrm{~mm}^{2}$ and $0.02-0.055 \mu \mathrm{A}$, respectively. An analyzing dose of 1 to $5 \mu \mathrm{C}$ was collected at each data point, providing counting statistics with a statistical error $<5 \%$. 
Protons emitted from the $\mathrm{D}\left({ }^{3} \mathrm{He}, \mathrm{p}\right){ }^{4} \mathrm{He}$ nuclear reaction with energies in the range 12.1-13.4 MeV, depending on the incident ${ }^{3} \mathrm{He}$ energy, were detected using a wide-angle surface-barrier detector with a solid angle of $0.14 \mathrm{sr}$ and a depletion depth of $700 \mu \mathrm{m}$, located at a laboratory angle $\theta=135^{\circ}$. A Mylar absorber foil with a thickness of $12 \mu \mathrm{m}$ was positioned in front of the detector in order to absorb elastically scattered ${ }^{3} \mathrm{He}$ ions and $\alpha$ particles from the $\mathrm{D}\left({ }^{3} \mathrm{He}, \alpha\right) \mathrm{H}$ nuclear reaction. Highly energetic protons from the $\mathrm{D}\left({ }^{3} \mathrm{He}, \mathrm{p}\right)^{4} \mathrm{He}$ can reach the detector.

Deuterium depth profiles were calculated by an iterative method. The first guess profile was made with the SIMNRA $[12,13]$ program, which calculates the proton yield for an energy of the incident ${ }^{3} \mathrm{He}$ beam. Then, the guess profile was improved, and the calculations repeated until the calculated proton yield as a function of incident ${ }^{3} \mathrm{He}$ energy agreed with the measured one. We used the detailed cross section of the $\mathrm{D}\left({ }^{3} \mathrm{He}, \mathrm{p}\right)^{4} \mathrm{He}$ nuclear reaction reported in Ref. [14].

\section{Results and discussion}

Figure 2 show the measured (points) and calculated (lines) proton yields for derivation of $\mathrm{D}$ profiles as a function of the applied ${ }^{3} \mathrm{He}$ energy at the divertor region samples without $\mathrm{H}$ discharges. The proton yields were normalized to an analyzing dose of $1 \mu \mathrm{C}$. Figure 3 (a)-(d) show the D depth profiles obtained by the SIMNRA program for (a) the inner divertor, (b) the outer divertor, (c) the dome top and (d) the outer dome wing samples. The 
analyzed depth was $14 \times 10^{23}$ carbon atoms $/ \mathrm{m}^{2}$, corresponding to a linear depth of $16.4 \mu \mathrm{m}$ for carbon materials used for divertor target tiles with the density of $1.7 \mathrm{~g} / \mathrm{cm}^{3}$. In the inner divertor region, thick re-deposition layer up to $200 \mu \mathrm{m}$ was observed $[11,15]$. Considering that the density of the re-deposition layer was $0.91 \mathrm{~g} / \mathrm{cm}^{3}[16]$, the depth of $14 \times 10^{23}$ carbon atoms $/ \mathrm{m}^{2}$ corresponds to a linear depth of $30.7 \mu \mathrm{m}$ for re-deposition layers on the ID sample.

In the surface region in Fig. 3 (a)-(d), D concentrations without $\mathrm{H}$ discharges were considerably higher than those with $\mathrm{H}$ discharges. The highest concentration (19 at.\%) was found at the surface of the inner divertor area (ID). However in the deeper region of all samples except for DM1, D concentrations without $\mathrm{H}$ discharges were lower than those with $\mathrm{H}$ discharges. These results indicate that $\mathrm{H}$ discharges can remove $\mathrm{D}$ trapped only in the shallow region. On the other hand, the D concentration of OD was relatively low (2.6 at. \%) even in the surface, because the surface temperature of the outer divertor tile was high as mentioned in Section 2.1.

Figure 4 compares the integrated deuterium retention within the analyzed depth $(14 \times$ $10^{23}$ carbon atoms $/ \mathrm{m}^{2}$ ) for divertor samples. The highest and lowest $\mathrm{D}$ retentions were found in the outer dome wing (DM2) and the outer divertor (OD), respectively, in the both cases of with and without $\mathrm{H}$ discharges. Only in the case of DM1 sample, the D retention with the $\mathrm{H}$ discharges $\left(0.39 \times 10^{22} \mathrm{D}\right.$ atoms $\left./ \mathrm{m}^{2}\right)$ was lower than that without $\mathrm{H}$ discharges $\left(1.25 \times 10^{22} \mathrm{D}\right.$ atoms $/ \mathrm{m}^{2}$ ). However, as for the other three tiles (ID, DM2 and OD), the D retentions without $\mathrm{H}$ discharges were lower than those with $\mathrm{H}$ discharges. 


\section{Conclusions}

Depth profiles of deuterium trapped in graphite tiles not exposed to hydrogen discharges just before air ventilation of JT-60U were determined based on the $\mathrm{D}\left({ }^{3} \mathrm{He}, \mathrm{p}\right){ }^{4} \mathrm{He}$

resonant nuclear reaction caused by ${ }^{3} \mathrm{He}$ of different energies. The highest concentration (19 at.\%) was found at the surface of the inner divertor area, which was significantly higher than that exposed to $\mathrm{H}$ discharges at the same location. However in the deeper region, $\mathrm{D}$ concentrations without $\mathrm{H}$ discharges were lower than those with $\mathrm{H}$ discharges in 3 of 4 samples. These results indicate that $\mathrm{H}$ discharges can remove $\mathrm{D}$ trapped only in the shallow region.

\section{Acknowledgements}

The present authors wish to thank Mr. J. Dorner and Mr. M. Fußeder for their technical assistance with the ${ }^{3} \mathrm{He}$ beam analyses. This work was carried out as an IPP - JAEA collaboration, and was a joint research effort between Japanese universities and JAEA. We would like to thank the JT-60 team for their contribution to the operation and the experimental setup of JT-60U. 
References

[1] G. Federici, C.H. Skinner, J.N. Brooks, et al., Nucl. Fusion 41 (12R) (2001) 1967.

[2] J.P. Coad, N. Bekris, J.D. Elder, et al., J. Nucl. Mater. 290-293 (2001) 224.

[3] K. Masaki, T. Tanabe, Y. Hirohata, et al., Nucl. Fusion 47 (2007) 1577.

[4] H. Hirohata, T. Tanabe, Y. Oya, et al., J. Nucl. Mater. 363-365 (2007) 854.

[5] T. Tanabe, K. Miyasaka, K. Masaki, et al., J. Nucl. Mater. 307-311 (2002) 1441.

[6] Y. Hirohata, Y. Oya, H. Yoshida, et al., J. Nucl. Mater. 329-333 (2004) 785.

[7] T. Shibaraha, T. Tanabe, Y. Hirohata, et al., Nucl. Fusion 46 (2006) 841.

[8] T. Hayashi, K. Sugiyama, K. Krieger, et al., J. Nucl. Mater. 363-365 (2007) 904.

[9] T. Hayashi, K. Ochiai, K. Masaki, et al., J. Nucl. Mater. 349 (2006) 6.

[10] K. Sugiyama, T. Hayashi, K. Krieger, et al., J. Nucl. Mater. 363-365 (2007) 949.

[11] Y. Gotoh, T. Tanabe, Y. Ishimoto, et al., J. Nucl. Mater. 357 (2006) 138.

[12] M. Mayer, SIMNRA User's Guide, Tech. Report IPP 9/113, Max-Planck-Institut fur Plasmaphysik, Garching, Germany, 1997.

[13] M. Mayer, in: J.L. Duggan,I. Morgan (Eds.), AIP Conference Proceedings, vol. 475,American Institute of Physics, 1999, p. 541.

[14] V. Kh. Alimov, M. Mayer and J. Roth, Nucl. Instr. and Meth. B 234 (2005) 169.

[15] Y. Gotoh, J. Yagyu, K. Masaki, et al., J. Nucl. Mater. 313-316 (2003) 370.

[16] Y. Ishimoto, Y. Gotoh, T. Arai, et al., J. Nucl. Mater. 350 (2006) 301. 
Figure captions

Fig. 1

Poloidal locations of analyzed samples in the W-shaped divertor of JT-60U.

Fig.2

Measured (points) and calculated (lines) proton yields for D depth profiles.

Fig. 3

Deuterium depth profiles in samples of the divertor region. Note that the D concentration scales in part (b) is different from the others.

Fig. 4

Distribution of deuterium retention in the divertor region. 


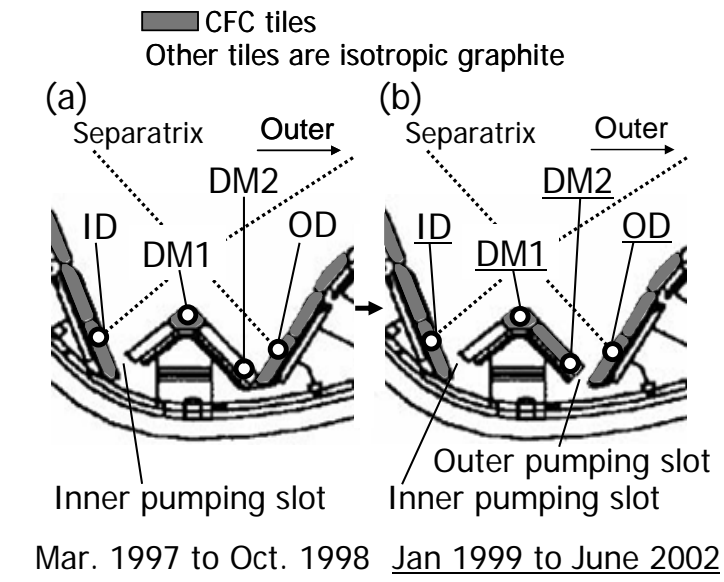

Fig. 1 


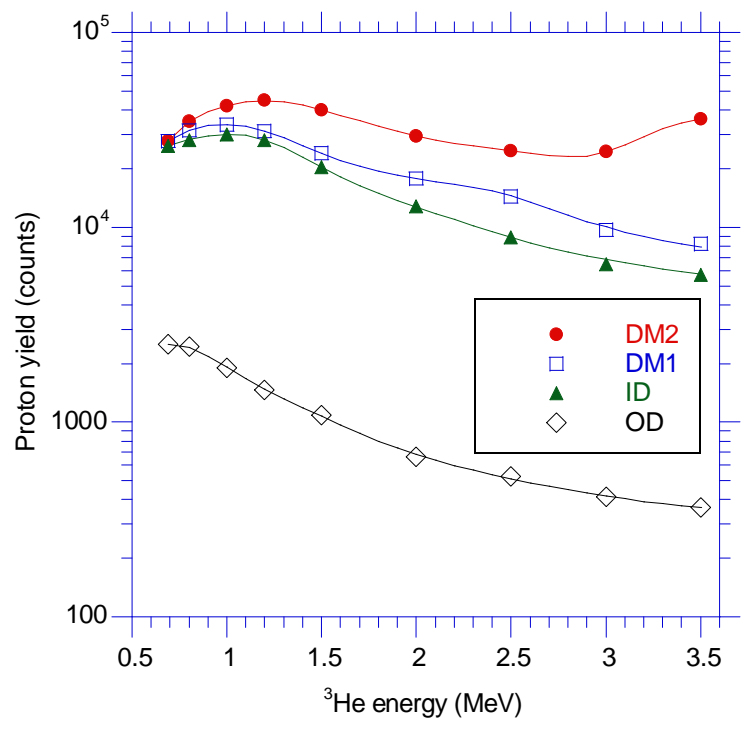

Fig. 2

(Color online) 

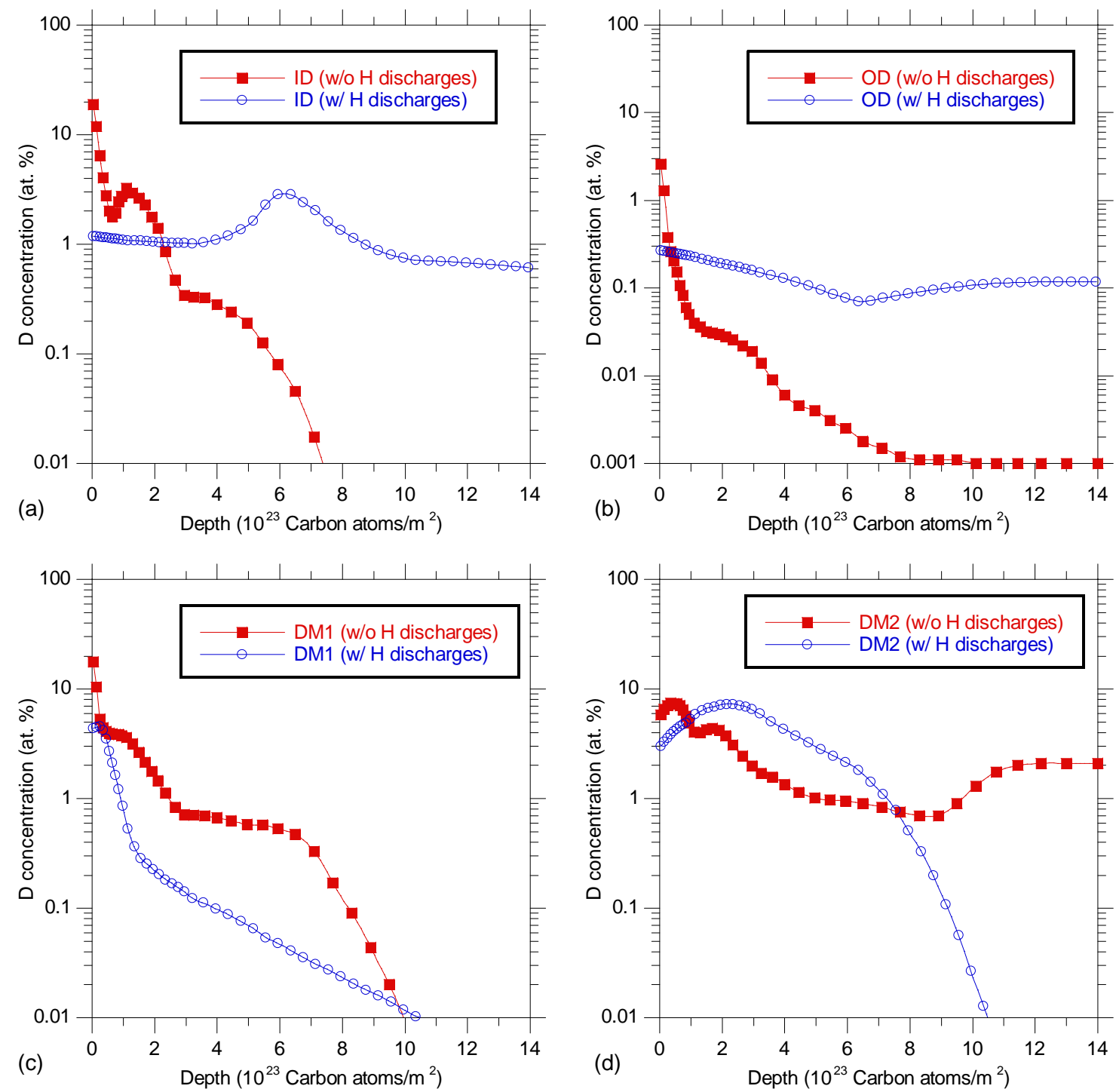

Fig. 3

(Color online) 


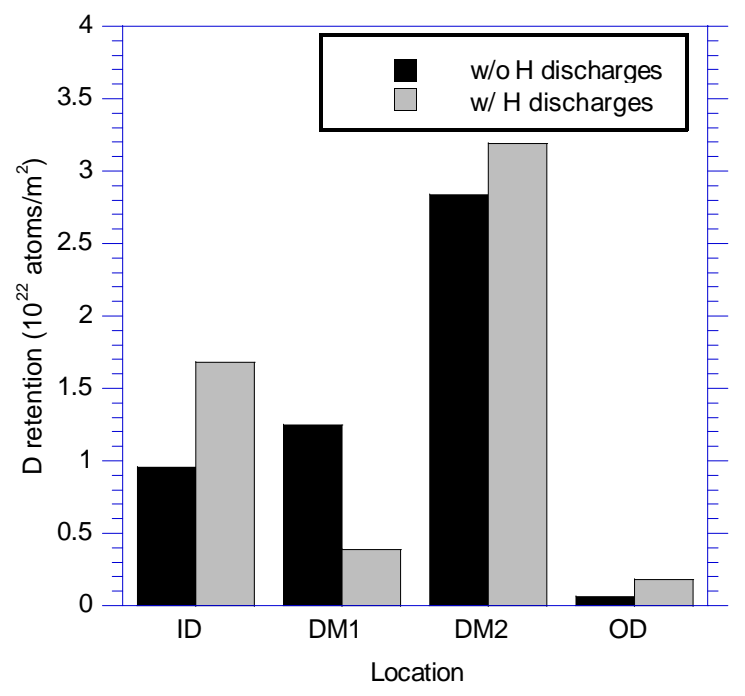

Fig. 4 (Color online) 